\title{
THE EFFECT OF WEAVE CONSTRUCTION ON TEAR STRENGTH OF WOVEN FABRICS
}

\author{
Selin Hanife Eryuruk ${ }^{1}$ and Fatma Kalaoğlu ${ }^{1}$ \\ ${ }^{1}$ Istanbul Technical University, Textile Technologies and Design Faculty, Istanbul, Turkey \\ Corresponding Author: eryuruk@itu.edu.tr, tel.0090 212293 13 00, fax. 00902122491767
}

\begin{abstract}
:
The tear strength of a woven fabric is very important, since it is more closely related to serviceability of the fabric. Tearing strength of the fabrics depend on the mobility of the yarn within the fabric structure. In this study, the tearing strength of four types of fabrics warp rib, weft rib, ripstop and plain weave were analysed, which were produced in different densities and with filament and texturised polyester yarns.
\end{abstract}

\section{Keywords:}

Tear strength, warp rib, weft rib, ripstop, plain weave

\section{Introduction}

Tearing can be described as the sequential breakage of yarns or groups of yarns along a line through a fabric. It is one of the most common types of failure in textile materials and in many cases, serves to terminate their useful life. The tearing strength is often used to give a reasonably direct assessment of serviceability than the tensile strength and a fabric with low tearing strength is generally an inferior product. In the case of tensile loading, all the yarns in the direction of loading share the load; in tear loading only one, two or at most a few yarns share the load. The tearing strength is affected by changes in yarn geometry, fabric geometry, relaxation of the fibres and their frictional characteristics. The movement of the yarns will be restricted in tight constructions and results in a low tearing strength. Loose and open constructions allow yarns to move and group together, thus result in a high tearing strength. The tear strength is high with the designs having groups of yarns woven together, such as rib weaves and basket weaves [1].

The studies on tearing strength began with Krook and Fox [2]. They named the triangular distortion at the active region of tearing as 'del'. They stated that fabric structure is more important, which determines the del shape in the region of tear and strongly affect the tear strength of the fabric. At the beginning of a tongue tear test when the loads on the tails is first applied, the cross yarns pull out of the fabric and become del yarns, the crimp is taken out of both sets of yarns near the del and crimp exchange occurs within the untorn fabric, the untorn fabric ahead of the del becomes jammed in the direction of tear. The more easily the cross yarns pull out of the fabric, the longer the del yarns and the longer the del resulting high tear strength. Moreover, they found that if the density of longitudinal yarns was decreased (while holding the number of transverse yarns constant), the average tear strength of a sample increased. On the other hand, there was little effect on the measured tearing strength if the density of the transverse system of yarns was altered (while holding the number of longitudinal yarns constant). Furthermore, they stated that increased tear resistance was achieved by using yarns with higher tensile strength or by decreasing the effect of friction in the fabric through the use of more slippery yarns or longer floats. Hager also studied tear strength [3]. Morton investigated fabric strength in relation to yarn properties and density of structure [4]. O'Brien and Weiner presented the strength and water-resistance data for a series of lightweight cotton fabrics [5].

Teixeira et al. indicated some of the important factors affecting the tearing resistance of a fabric. These factors are the amount and type of weave distortion in and in the area around the del, relative extensibility of the fabric loaded ahead of the del, loadelongation curves of the del yarns, breaking strength of the del yarns and extensibility of the specimen tails which depend strongly on force required to pull a yarn out of the fabric, crimp level and crimp balance, interyarn spacing in the fabric, and in-plane fabric deformability [6]. Taylor compared the tearing strength values of similar constructed cloths containing single picks and double picks. The tests were done by using the ballistic method. The double-pick clothes had the tearing strength values of about twice compared with the values for the single-pick clothes [7]. Scelzo et al. investigated the influences of physical parameters such as weave density and yarn spinning system on the tearing behaviour of fabrics $[8,9]$. They showed that less dense weaves had higher tear strengths for both ring and rotor spun cotton fabrics. They concluded that there were three components of tear that must be included in any tearing model: resistance to pull-out, resistance to jamming and the resistance to yarn breakage $[10,11,12]$. Hu and Xu studied the tearing properties of coated multi-axial warp knitted fabrics. They analysed the typical tearing load-extension curves and influences of the different tearing testing conditions and found that the tearing properties of the coated multi-axial warp fabric were different from those of the coated woven fabrics and that 
they depended on the tearing directions and tearing methods [13]. Khedher et al. studied the effect of different launderings (stone wash, enzyme wash, mixed wash and rinse), special treatments applied during the manufacturing process of garment washing (brushing, sanding, resin-treatment, bleachtreatment, permanganate-spray and softening) and their effects on the fabric mechanical properties such as tear strength and breaking strength. They showed that all these treatments, applied to obtain more worn appearance and aged look has decreased the mechanical properties of fabrics [14]. Teli et al. have evaluated the strength properties of the fabric with respect to tensile, tear and bursting strength and correlated the results with respect to the yarn count, twist multiplier and picks per inch of the fabric using regression equations [15]. Chen et al. studied on the tear behaviour of coated fabric using the finite element method [16].

Rib weaves are derived from plain weave. Due to $1 / 1$ interlacing, the plain weave has the maximum level of yarn crimp in the structure. As a result of this, the plain weave has modulus compared to other weave patterns that have less crimp and floating yarn in their structure. To increase the strength of the plain fabrics, rib construction of fabrics are developed, especially for heavy application areas. Rib fabrics can be produced as warp rib, weft rib and ripstop, which has rib construction in both directions. Warp ribs formula has $1 / 1$ interlacing in the filling direction and an interlacing pattern different than $1 / 1$ in the warp direction. This results in a design that has ribs or texture ridges across the fabric in the warp direction, which is caused by grouping of filling yarns. Weft rib formula has $1 / 1$ interlacing in the warp direction and an interlacing pattern different than in the weft direction. This results in a design that has ribs or texture ridges across the fabric in the filling direction. These ribs are formed by grouping of warp yarns. Ripstop fabrics are similar to basket weaves, which are produced by combining warp and weft ribs. In basket weaves, warp and filling yarns are grouped and they interlace together. Basket weaves can be classified as common formula or uncommon formula [17].

It is apparent from the literature that the effect of weave construction on tear strength of cotton yarn is mostly studied but there is no study comparing the tearing performance of filament and textured fabrics having different weave patterns.

\section{Material and method}

\subsection{Material}

In this study, 24 woven fabrics were produced. The 150 denier $350 \mathrm{twist} / \mathrm{cm}$ filament polyester yarn was used as warp yarn for all of the fabrics. Two different weft yarns of 100 denier (filament and texturised) were used to produce woven fabrics in three different weft densities while the warp density was kept constant at $64 \mathrm{warp} / \mathrm{cm}$. The fabric weave patterns are shown on Figure 1-4.The fabric properties are given in Table 1.

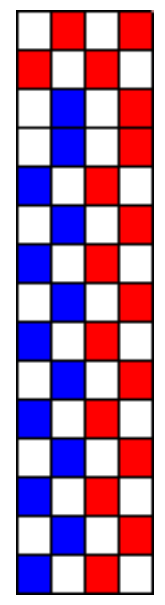

Figure 1: Warp rips weave

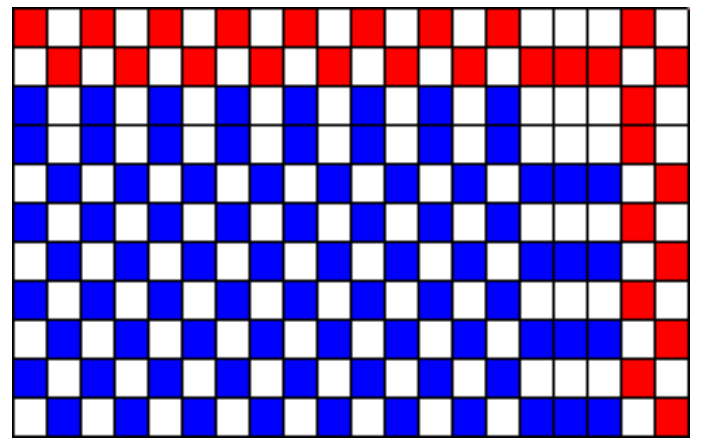

Figure 3: Ripstop weave
Figure 2: Weft rips weave

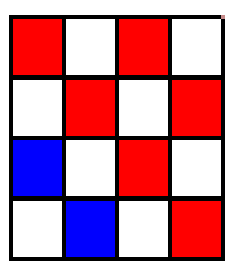

Figure 4: Plain weave 
Table 1. Fabric properties used in experiments

\begin{tabular}{|c|c|c|c|c|c|c|c|c|c|}
\hline $\begin{array}{l}\text { Fabric } \\
\text { code }\end{array}$ & $\begin{array}{l}\text { Weave } \\
\text { types }\end{array}$ & $\begin{array}{l}\text { Weft } \\
\text { thread }\end{array}$ & $\begin{array}{c}\text { Weft } \\
\text { density } \\
\text { (weft/cm) }\end{array}$ & $\begin{array}{l}\text { Fabric } \\
\text { weight } \\
\left(\mathrm{g} / \mathrm{m}^{2}\right)\end{array}$ & $\begin{array}{l}\text { Thickness } \\
\text { (mm) }\end{array}$ & $\begin{array}{l}\text { Warp } \\
\text { tearing } \\
\text { strength } \\
\text { (N) }\end{array}$ & $\begin{array}{c}\text { Std. } \\
\text { dev. of } \\
\text { warp } \\
\text { tearing }\end{array}$ & $\begin{array}{c}\text { Weft } \\
\text { tearing } \\
\text { strength } \\
\text { (N) }\end{array}$ & $\begin{array}{l}\text { Std. dev. } \\
\text { of weft } \\
\text { tearing }\end{array}$ \\
\hline 1 & \multirow{6}{*}{$\begin{array}{l}\text { Warp } \\
\text { Rips }\end{array}$} & \multirow{3}{*}{ Textured } & 25 & 179.7 & 0.51 & 16.59 & 0.56 & 40.42 & 1.64 \\
\hline 2 & & & 18 & 162.1 & 0.42 & 23.77 & 0.98 & 68.54 & 0.88 \\
\hline 3 & & & 20 & 165.6 & 0.52 & 20.99 & 1.12 & 62.60 & 0.96 \\
\hline 4 & & \multirow{3}{*}{ Filament } & 18 & 156.5 & 0.34 & 23.75 & 0.66 & 76.13 & 0.42 \\
\hline 5 & & & 20 & 163.9 & 0.34 & 19.73 & 1.54 & 65.05 & 0.52 \\
\hline 6 & & & 25 & 180.4 & 0.45 & 16.13 & 0.68 & 38.55 & 0.79 \\
\hline 7 & \multirow{6}{*}{ Weft Rips } & \multirow{3}{*}{ Textured } & 20 & 177.2 & 0.44 & 36.13 & 0.17 & 40.82 & 1.90 \\
\hline 8 & & & 14 & 162.7 & 0.46 & 49.19 & 0.94 & 55.80 & 1.33 \\
\hline 9 & & & 16 & 167.7 & 0.46 & 44.51 & 0.05 & 66.64 & 0.97 \\
\hline 10 & & \multirow{3}{*}{ Filament } & 20 & 172.4 & 0.35 & 34.26 & 1.02 & 40.40 & 0.82 \\
\hline 11 & & & 16 & 162.7 & 0.35 & 45.00 & 0.75 & 53.64 & 0.93 \\
\hline 12 & & & 14 & 155.6 & 0.34 & 51.46 & 1.45 & 81.36 & 0.46 \\
\hline 13 & \multirow{6}{*}{ Ripstop } & \multirow{3}{*}{ Textured } & 20 & 172.5 & 0.41 & 34.87 & 0.58 & 49.45 & 1.14 \\
\hline 14 & & & 16 & 161.2 & 0.36 & 38.96 & 0.77 & 66.47 & 1.77 \\
\hline 15 & & & 14 & 154.6 & 0.35 & 39.48 & 0.39 & 78.20 & 2.20 \\
\hline 16 & & \multirow{3}{*}{ Filament } & 20 & 177.4 & 0.53 & 34.18 & 1.25 & 48.54 & 0.99 \\
\hline 17 & & & 16 & 165.2 & 0.50 & 41.40 & 0.98 & 64.75 & 1.05 \\
\hline 18 & & & 14 & 157.3 & 0.46 & 45.12 & 0.86 & 81.51 & 1.25 \\
\hline 19 & \multirow{6}{*}{$\begin{array}{l}\text { Plain } \\
\text { weave }\end{array}$} & \multirow{3}{*}{ Textured } & 25 & 178.5 & 0.38 & 15.51 & 0.51 & 39.60 & 0.70 \\
\hline 20 & & & 20 & 167.1 & 0.39 & 20.11 & 0.69 & 43.97 & 0.85 \\
\hline 21 & & & 18 & 162.0 & 0.40 & 22.56 & 1.10 & 46.37 & 0.62 \\
\hline 22 & & \multirow{3}{*}{ Filament } & 25 & 177.0 & 0.31 & 16.69 & 1.14 & 43.28 & 1.23 \\
\hline 23 & & & 20 & 162.5 & 0.31 & 20.99 & 0.74 & 51.70 & 1.11 \\
\hline 24 & & & 18 & 154.8 & 0.31 & 24.81 & 0.85 & 68.82 & 0.96 \\
\hline
\end{tabular}

ISO 13937-2- Textiles-Tearproperties of fabrics -- Part 2: Determination of tearforce of trouser-shaped test specimens (Singletearmethod) was used to make the tear tests. A rectangular test specimen was cut from the test specimen (Figure 5). Five specimens for warp tearing and five specimens for weft tearing were prepared. The clamps of the tensile testing machine were adjusted at a distance of $100 \mathrm{~mm}$ apart, taking care that the clamps were properly aligned and parallel to each other. Also, the tensile testing machine was adjusted to give a constant rate of jaw separation of $100 \mathrm{~mm} / \mathrm{min}$. The legs of the samples were fastened to the clamps of the device along a straight line and pulled to tear the fabric. Applied force to continue the tear was recorded up to a specified length.

\section{Results}

Figure 6 shows the tear results of warp rib and weft rib fabrics together. For all fabric types, it is seen that weft tearing strength values were found greater than the warp tearing strength values as expected. In both the weave types, there is a distinct loss in tear strength as the number of threads per metre in either direction increases. In this study, the warp density is $65 \mathrm{warp} / \mathrm{cm}$ and weft densities are between 14 and 20 weft $/ \mathrm{cm}$, therefore, it is found that for all of the samples, the weft tear strength is significantly higher than warp tear strength. Moreover, as the weft density (weft/cm) increased, tearing strength of the fabric decreased for all types of fabrics. These results are parallel to 
1: Sign for the end point of tear 2: slit

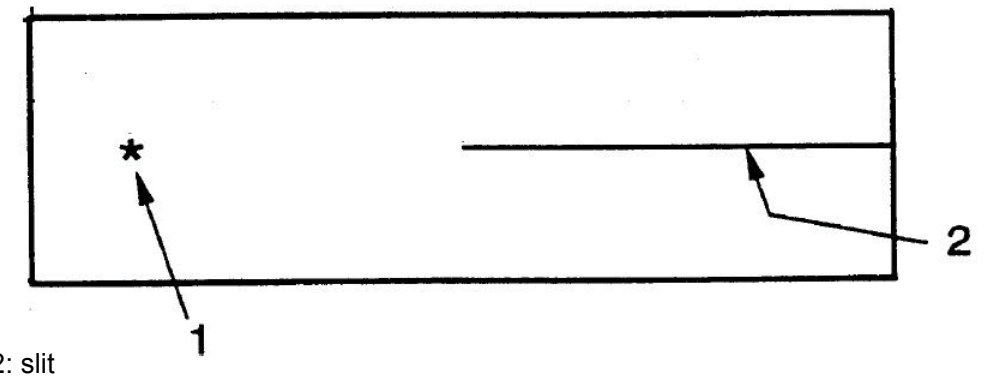

Figure 5: Sample preparation for tear test (ISO 13937-2 2000)

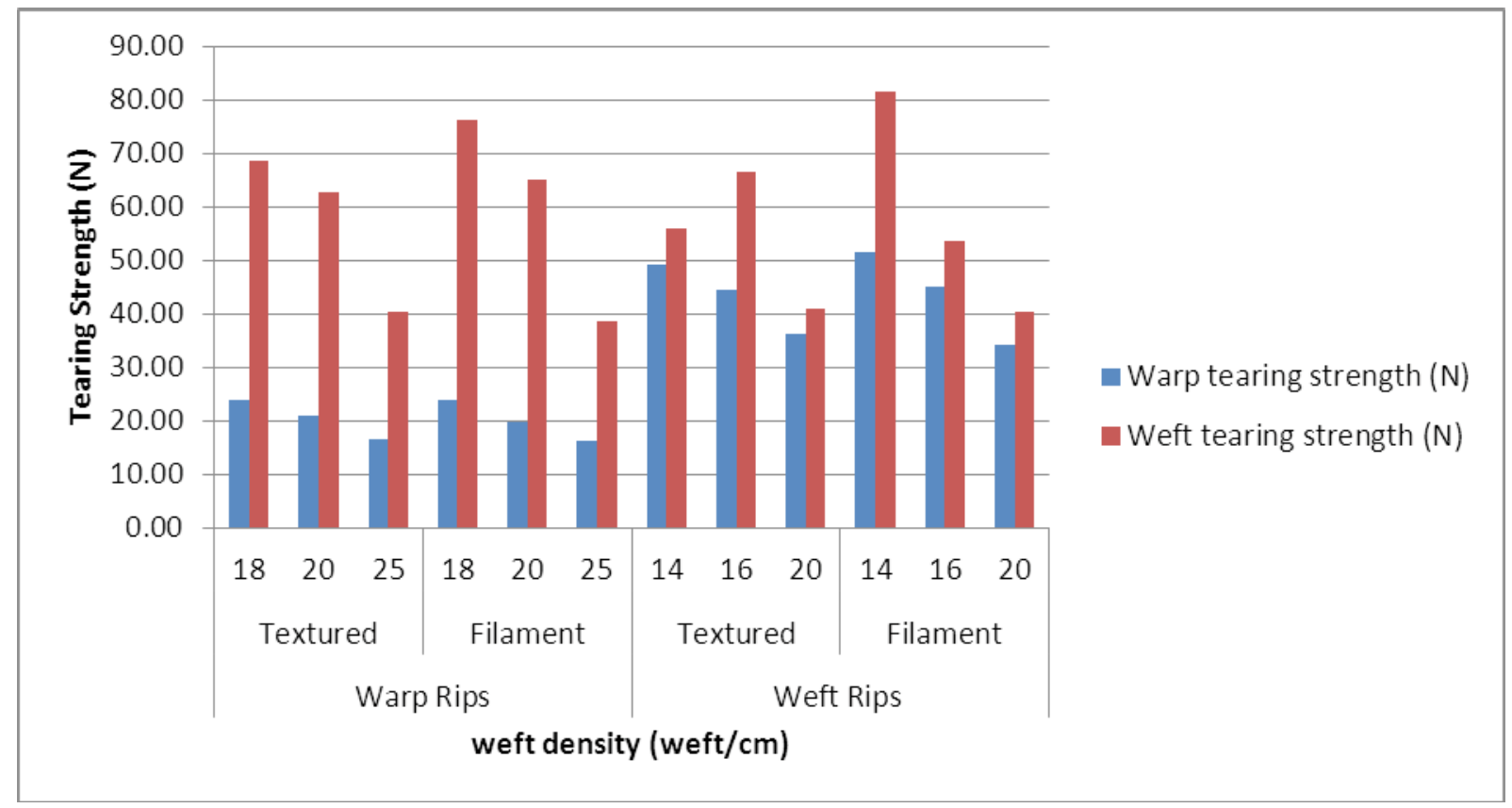

Figure 6. Warp rips and weft rips fabrics tearing strength results

the findings of Krook and Fox. They discovered that the tear strength of the fabric increases as the density of longitudinal yarns is decreased.

Figure 7 shows the tearing strength results of ripstop woven fabrics, which can be considered as a modified basket weave. Again, reverse relationship was found between the weft density and tearing strength values as stated by Teixeira, Krook and Fox. As the weft/cm increased, tearing strength values of the fabrics decreased. For the density of $14 \mathrm{weft} / \mathrm{cm}$, weft filament and weft-textured fabrics had the highest tearing strength values. Similar to the warp and weft rib fabrics, it is found that warp tearing strength is significantly lower than weft direction for ripstop fabrics due to high yarn density in warp direction.

Figure 8 shows the tearing strength results of plain weave fabrics. Similar to the previous results, it is seen that warp tearing strength is significantly lower than weft direction for plain woven fabrics. Moreover, it is seen that there is a reverse relationship between the weft density and tearing strength values, as the weft increased, tearing strength values of the fabrics decreased. It is clearly seen from the figure that weft filament fabrics had the highest tearing strength values for all weft density values. Furthermore, warp-textured fabrics had the lowest tearing strength values. Krook and Fox stated that increased tear resistance could be achieved by using yarns with higher tensile strength or by decreasing the effect of friction in the fabric through the use of more slippery yarns or longer floats. Tear strength of fabrics depend on the mobility of the yarns within the fabric structure. Filament yarns permit mobility of the yarns due to their slippery surface properties, low coefficient of yarn-to-yarn friction. Taylor agreed that del deformation requires yarn slippage. He concluded that the changes in longitudinal yarn spacing due to slippage of transverse yarn are important. According to Scelzo (1994), there are two resistances acting on a yarn throughout its movement into jammed configuration, which means sliding of transverse yarns along the longitudinal yarns in tongue tear sample. One of the resistances is elastic and the other one is frictional. When a del yarn is being pulled forward, both of these forces oppose this motion. Scelzo concluded that a high resistance to tear requires a large number of yarns to be incorporated into the del zone. The weave construction allowing for more mobility and consequently more del yarns will yield a higher strength. If the yarns cannot be pulled out from the fabric easily due to friction of yarns, it will prevent jamming of the yarn in the del resulting lower tear strength. 


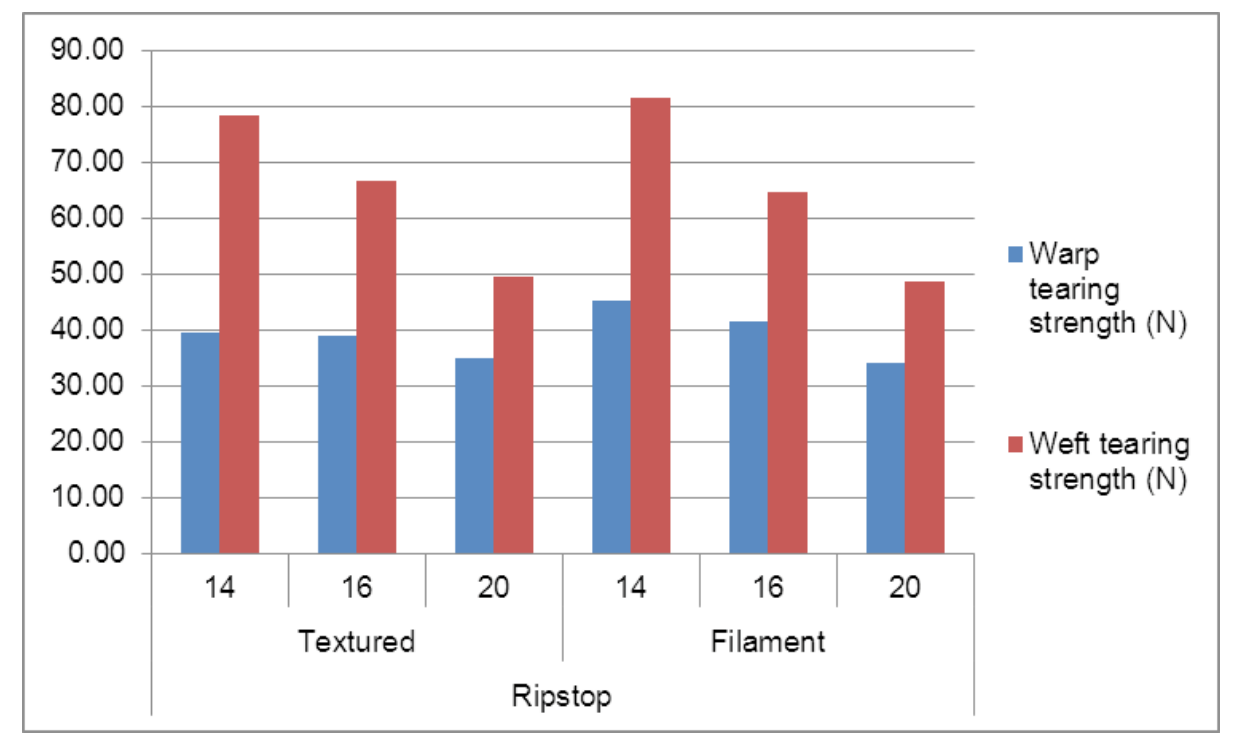

Figure 7: Ripstop fabrics tearing strength results

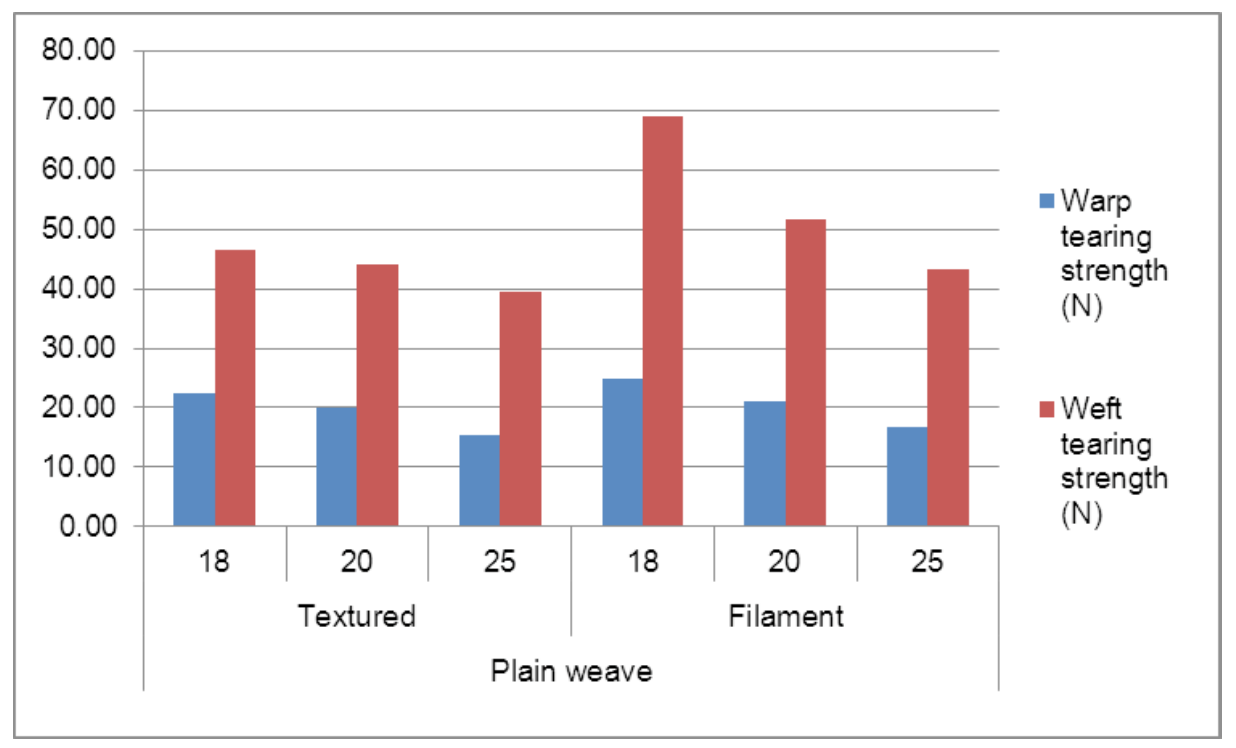

Figure 8: Plain fabrics tearing strength results

Figure 9 shows the tearing strength results of all types of fabrics that have the same weft density of $20 \mathrm{weft} / \mathrm{cm}$. It is seen that the highest tear strength is obtained with the warp rips weave woven with filament yarns. The weave pattern influences the tearing strength by controlling the relative frequency of yarn crossing points in the fabric. This has a direct effect on both the ease of deformation of the fabric and the number of yarns breaking together. In a weave with many crossovers per $\mathrm{cm}$, the gripping action between warp and filling threads will tend to be high and thus increase the yarn pull-out force when compared to the fabrics with long floats. This increase in pull-out force resulting from weave will decrease the realisable tear strength of the fabric. For this reason, the plain weave is weaker in tear than the basket weave. Teixeira stated that $2 / 2$ basket weave is more than twice as strong as the $1 / 1$ plain weave.

Statistical analysis had been carried out by using IBM SPSS Statistics 20. The Paired-Samples T Test procedure was used to test the hypothesis of relationship between two variables. $\mathrm{H}_{0}$ hypothesis (e.g. there is no relationship between weft tear strength and weft density) was tested across the alternative hypothesis and the paired samples correlations and hypothesis tests results for weft tear values are shown in Tables 2 and 3 . There was found a negative correlation between weft tear values and weft density $(-0.765)$. As the weft density increased, weft tear values decreased. Also, between weft tear values and weight, there was found a negative correlation $(-0.850)$, which means as the weight increased, weft tear strength decreased. On the other hand, a negative correlation value between weft tear value and thickness was not significant. Because the significance value 0.000 was less than 0.05 , there was significant difference in the weft tear values, according to weft density values and weight values.

Table 4 and 5 show the paired samples correlations and hypothesis tests results for warp tear values. There was a negative correlation between warp tear values and weft density $(-0.830)$ and weft tear values and weight $(-0.409)$. However, correlation between warp tear values and thickness values were not significant. Because the significance value 0.000 was 


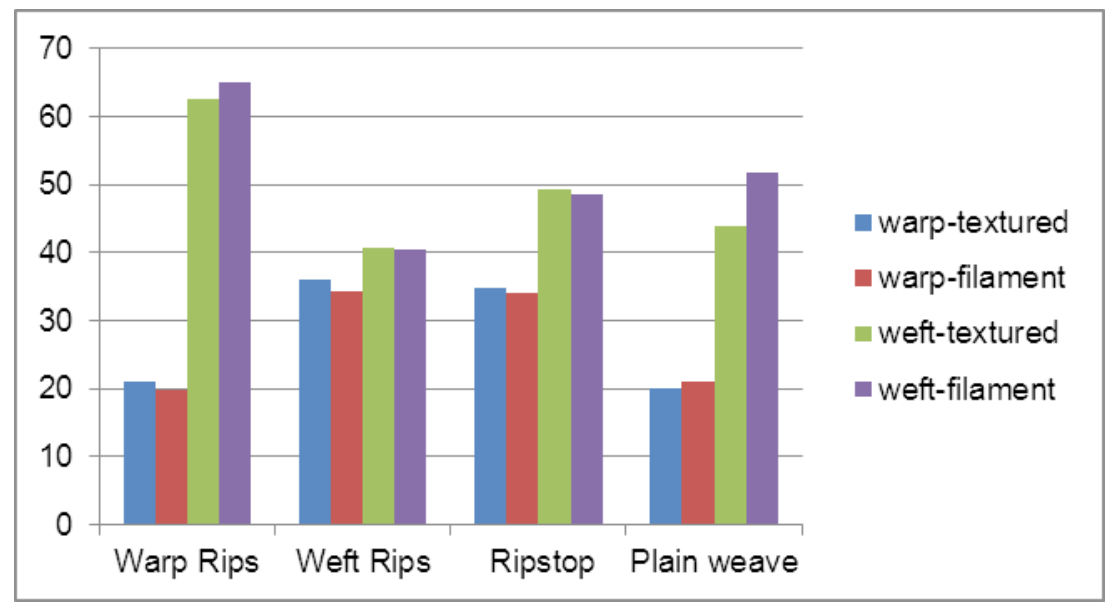

Figure 9: Tear strength results of $20 \mathrm{weft} / \mathrm{cm}$ fabrics

Table 2: Paired samples correlations for weft tear values

\begin{tabular}{|c|c|c|c|c|}
\hline \multicolumn{5}{|c|}{ Paired samples correlations } \\
\hline \multicolumn{2}{|c|}{} & $\mathbf{N}$ & Correlation & Significance \\
\hline Pair 1 & Weft tear \& weft density & 24 & -0.765 & 0.000 \\
\hline Pair 2 & Weft tear \& weight & 24 & -0.850 & 0.000 \\
\hline Pair 3 & Weft tear \& thickness & 24 & -0.144 & 0.501 \\
\hline
\end{tabular}

Table 3: Paired samples tests for weft tear values

\begin{tabular}{|c|c|c|c|c|c|c|c|c|c|}
\hline \multicolumn{10}{|c|}{ Paired samples test } \\
\hline & & \multicolumn{5}{|c|}{ Paired differences } & \multirow{3}{*}{$\mathbf{t}$} & \multirow{3}{*}{ df } & \multirow{3}{*}{$\begin{array}{c}\text { Significance } \\
\text { (2-tailed) }\end{array}$} \\
\hline & & \multirow[t]{2}{*}{ Mean } & \multirow[t]{2}{*}{$\begin{array}{l}\text { Standard } \\
\text { deviation }\end{array}$} & \multirow{2}{*}{$\begin{array}{l}\text { Standard } \\
\text { error } \\
\text { mean }\end{array}$} & \multicolumn{2}{|c|}{$\begin{array}{l}95 \% \text { confidence } \\
\text { interval of the } \\
\text { difference }\end{array}$} & & & \\
\hline & & & & & Lower & Upper & & & \\
\hline Pair 1 & $\begin{array}{l}\text { Weft } \\
\text { tear - weft } \\
\text { density }\end{array}$ & 38.359 & 17.195 & 3.510 & 31.098 & 45.619 & 10.929 & 23 & 0.000 \\
\hline Pair 2 & $\begin{array}{l}\text { Weft tear - } \\
\text { weight }\end{array}$ & -109.333 & 21.930 & 4.476 & -118.593 & -100.073 & -24.420 & 23 & 0.000 \\
\hline Pair 3 & $\begin{array}{l}\text { Weft tear - } \\
\text { thickness }\end{array}$ & 56.788 & 14.330 & 2.925 & 50.737 & 62.839 & 19.414 & 23 & 0.000 \\
\hline
\end{tabular}

less than 0.05 for pair 1 and 2, there was found a significant difference in the warp tear values, according to weft density values and weight values.

Regression analysis was also conducted and results are shown in Table 6. It is clearly seen from the table that if the dependent variable was selected as warp tear strength, coefficient of determination $\left(R^{2}\right)$ is 0.690 for weft density. Weft density was found highly correlated with warp tear strength and this clearly demonstrated with regression analysis. If the dependent variable was selected as weft tear strength, coefficient of determination $\left(R^{2}\right)$ equals to 0.565 for weft density and 0.722 for weight. It proved that weight and weft density are highly correlated (negatively) with weft tear strength values.

\section{Conclusions}

Fabric structure is very important in determining the del shape in the region of tear and strongly affects the tear strength of the fabric. Tear strength of fabrics depend on the mobility of the yarns within the fabric structure. Plain fabrics had the low tearing strength due to loss of mobility. The weave pattern influences tearing strength, controlling the relative frequency of yarn crossing points in the fabric. This has a direct effect on both 
Table 4: Paired samples correlations for warp tear values

\begin{tabular}{|c|c|c|c|c|}
\hline \multicolumn{7}{|c|}{ Paired samples correlations } \\
\hline Pair 1 & Warp tear \& weft density & N & Correlation & Sig. \\
\hline Pair 2 & Warp tear \& weight & 24 & -0.830 & 0.000 \\
\hline Pair 3 & Warp tear \& thickness & 24 & -0.409 & 0.047 \\
\hline
\end{tabular}

Table 5: Paired samples tests for warp tear values

\begin{tabular}{|c|c|c|c|c|c|c|c|c|c|}
\hline \multicolumn{10}{|c|}{ Paired samples test } \\
\hline & & \multicolumn{5}{|c|}{ Paired differences } & \multirow{3}{*}{$\mathbf{t}$} & \multirow{3}{*}{ df } & \multirow{3}{*}{$\begin{array}{c}\text { Sig. } \\
\text { (2-tailed) }\end{array}$} \\
\hline & & \multirow{2}{*}{ Mean } & \multirow{2}{*}{$\begin{array}{c}\text { Std. } \\
\text { deviation }\end{array}$} & \multirow{2}{*}{$\begin{array}{l}\text { Std. } \\
\text { error } \\
\text { mean }\end{array}$} & \multicolumn{2}{|c|}{$\begin{array}{l}95 \% \text { confidence interval } \\
\text { of the difference }\end{array}$} & & & \\
\hline & & & & & Lower & Upper & & & \\
\hline Pair 1 & $\begin{array}{l}\text { Warp tear - } \\
\text { weft density }\end{array}$ & 11.841 & 14.818 & 3.025 & 5.58424 & 18.09826 & 3.915 & 23 & 0.001 \\
\hline Pair 2 & $\begin{array}{l}\text { Warp tear - } \\
\text { weight }\end{array}$ & -135.850 & 17.011 & 3.472 & -143.03346 & -128.66737 & -39.124 & 23 & 0.000 \\
\hline Pair 3 & $\begin{array}{l}\text { Warp tear - } \\
\text { thickness }\end{array}$ & 30.271 & 11.721 & 2.392 & 25.32147 & 35.22019 & 12.652 & 23 & 0.000 \\
\hline
\end{tabular}

Table 6: Regression analysis for warp tear and weft tear values

\begin{tabular}{|c|c|c|}
\hline Variables & $\mathbf{R}^{2}$ (warp tear) & $\mathbf{R}^{2}$ (weft tear) \\
\hline Weft density & 0.690 & 0.565 \\
\hline Weight & 0.168 & 0.722 \\
\hline Thickness & 0.014 & 0.021 \\
\hline
\end{tabular}

the ease of deformation of the fabric and the number of yarns breaking together. Rib fabrics had higher tear resistance than plain weave since two yarns act together against tear due to the construction. Parallel to the findings of earlier researchers, yarn density is found to be the most important parameter that significantly influences the tearing strength of the fabrics for all of the weave types. Fabrics woven with filament yarns had higher tear strength than texturised yarns, which is also in agreement with the literature that concluded the increased tear resistance could be achieved by decreasing the effect of friction in the fabric through the use of more slippery yarns. Filament yarns permit mobility of the yarns due to their slippery surface properties, low coefficient of yarn-to-yarn friction.

\section{References}

[1] Skelton, J., (1980), Tearing behaviour of woven fabrics, in J.W.S. Hearle et al "Mechanics of flexible fibre assemblies", Sijthoff \& Noordhoff, p. 243.Hu, J. and Chan, Y.F., (1998), Effect of Fabric Mechanical Properties on Drape, Textile Research Journal, 68 (1), 57-64.

[2] Krook, C. M. \& Fox, K. R., (1945), Study of the tongue tear test, Textile Research Journal, No.11, 389-396.
[3] Hager, O.B., Gagliardi,D.D. and Walker, H.B., (1947), Analysis of Tear Strength Hager, Textile Research Journal, vol. 17, 7: pp. 376-381.

[4] Morton, W.E., (1949), Some Observation on Fabric Strength in Relation to Yarn Properties and Density of Structure, Journal of Textile Institute, Volume 40 262-265, UK.

[5] O'Brien W.E. and Weiner, L.I.,(1954), A Study of Some Factors Affecting the Tear- and Water-Resistance of Lightweight Clothing and Tentage Fabrics, Textile Research Journal, vol. 24, 3: pp. 241-250.

[6] Teixeira, N. A.; Platt, M. M. \& Hamburger, W. J., (1955), Mechanics of elastic performance of textile materials: Part XII: Relation of certain geometric factors to the tear strength of woven fabrics, Textile Research Journal, No. 10, 838-861.

[7] Taylor, H. M., (1959), Tensile and tearing strength of cotton cloth, Journal Textile Institute, Vol. 50, T161-T188,UK.

[8] Scelzo, W. A.; Backer, S. \& Boyce, C., (1994a), Mechanistic role of yarn and fabric structure in determining tear resistance of woven cloth - Part I: Understanding tongue tear, Textile Research Journal, Vol. 64, No. 5, 291-304.

[9] Scelzo, W. A.; Backer, S. \& Boyce, C., (1994b), Mechanistic 
role of yarn and fabric structure in determining tear resistance of woven cloth. Part II: Modelling tongue tear, Textile Research Journal, Vol. 64, No. 6, 321-329.

[10] Painter E.V., Chu C.C. and Morgan H.M.,(1950), Testing Textiles on the Elmendorf Tear Tester [Textile Research Journal, vol. 20, 6: pp. 410-417.

[11] Sarma, G.V., Maji, M.R., Ranganathan, S.R. and Chipalkatti, V.B.,(1968), Studies in Wear Life of Normaland Special-Finished Woven Cotton Fabrics: Part I: Prediction of Tear Performance in Service on the Basis of Physical Properties, Textile Research Journal, vol. 38, 7: pp. 701-709.

[12] Sarma, G.V., Ranganathan, S.R., Chipalkatti, V.B. and Maji, M.R.,(1968), Studies in Wear Life of Normal- and SpecialFinished Woven Cotton Fabrics: Part II: A Theoretical Study of Tear Performance in Service, Textile Research Journal, vol. 38, 11: pp. 1118-1130.
[13] Hu, H. and Xu, Y., (2008), Tearing Properties Of Coated Multi-Axial Warp Knitted Fabric, AUTEX Research Journal, Vol 8, No.1, March, 13-16.

[14] Khedher, F., Dhouib, S., Msahli, S., Sakli F., (2009), The Influence of Industrial Finishing Treatments and Their Succession on The Mechanical Properties of Denim Garment, AUTEX Research Journal, Vol. 9, No.3, September, 93-100.

[15] Teli, M.D., Khare, A.R., Chakrabarti, R., (2008), Dependence Of Yarn And Fabric Strength On The Structural Parameters, AUTEX Research Journal, Vol. 8, No3, September, 63-67.

[16] Y-R. Chen, J-Y. Yu, Y-H. Di, "Study on the Tear Behaviour of Coated Fabric Using the Finite Element Method", International Journal of Nonlinear Sciences and Numerical Simulation, Volume 11, Issue 7 (Jul 2010).

[17] Adanur S., Handbook of weaving, Technomic publication, 2001, 28-30. 